\title{
Numerical prediction of the frictional losses in sliding bearings during start-stop operation
}

\author{
Florian KÖNIG*, Christopher SOUS, Georg JACOBS \\ Schinkelstraße 10, Aachen 52062, Germany \\ Received: 25 January 2020 / Revised: 15 April 2020 / Accepted: 09 June 2020 \\ (C) The author(s) 2020 .
}

Institute for Machine Elements and Systems Engineering, Rheinisch-Westfälische Technische Hochschule Aachen University,

\begin{abstract}
With the increased use of automotive engine start-stop systems, the numerical prediction and reduction of frictional losses in sliding bearings during starting and stopping procedures has become an important issue. In engineering practice, numerical simulations of sliding bearings in automotive engines are performed with statistical asperity contact models with empirical values for the necessary surface parameters. The aim of this study is to elucidate the applicability of these approaches for the prediction of friction in sliding bearings subjected to start-stop operation. For this purpose, the friction performance of sliding bearings was investigated in experiments on a test rig and in transient mixed elasto-hydrodynamic simulations in a multi-body simulation environment (mixed-EHL/MBS). In mixed-EHL/MBS, the extended Reynold's equation with flow factors according to Patir and Cheng has been combined on the one hand with the statistical asperity contact model according to Greenwood and Tripp and on the other hand with the deterministic asperity contact model according to Herbst. The detailed comparison of simulation and experimental results clarifies that the application of statistical asperity contact models with empirical values of the necessary inputs leads to large deviations between experiment and simulation. The actual distribution and position of surface roughness, as used in deterministic contact modelling, is necessary for a reliable prediction of the frictional losses in sliding bearings during start-stop operation.
\end{abstract}

Keywords: sliding bearing; friction; wearing-in; contact model, mixed elasto-hydrodynamic simulation

\section{Introduction}

In the last decade, automotive engine start-stop systems have led to a significant increase of start-stop cycles during the expected engine lifetime [1-4]. Low friction for the desired lifetime is a key requirement for engine bearings [5-7]. In sliding bearings, methods to improve the frictional performance range from improved mechanical design [8] over different lubricant formulation $[8,9]$ and novel bearing material solutions $[1,2,10]$ to modern surface engineering [11-13]. Furthermore, the frictional losses of sliding bearings can be reduced by wear-induced change of the contact geometry-hereafter referred to as wearing-in-under boundary or mixed-friction conditions [14-17].

In recent years, the frictional losses in sliding bearings in start-stop operation has gained a significant amount of attention. In a fundamental study, Bouyer and Fillon [18] studied the breakaway torque of sliding bearings made from bronze and white metal. For bronze bearings, the breakaway torque was proportional to the applied load and slightly influenced by shaft roughness. In contrast, the frictional losses in white metal bearings were significantly influenced by the load and the shaft's roughness. Thus, a nearly stationary breakaway coefficient of friction $(\mathrm{CoF})$

* Corresponding author: Florian KÖNIG, E-mail: florian.koenig@imse.rwth-aachen.de 


\begin{tabular}{|c|c|c|c|}
\hline \multicolumn{4}{|c|}{ Nomenclature } \\
\hline \multicolumn{2}{|c|}{ Latin letters } & $t$ & Time, s \\
\hline$A$ & Nominal contact area, $\mathrm{m}^{2}$ & $u$ & Sliding velocity, $\mathrm{m}$ \\
\hline$A_{\mathrm{a}}$ & Real contact area, $\mathrm{m}^{2}$ & $W$ & Bearing width, $\mathrm{m}$ \\
\hline$A_{\mathrm{f}}$ & Contact area of single asperity contact, $\mathrm{m}^{2}$ & Y & Yield stress, Pa \\
\hline$D$ & Bearing diameter, $\mathrm{m}$ & $z_{\mathrm{s}}$ & Summit height, $\mathrm{m}$ \\
\hline$F_{\mathrm{f}}$ & Friction force, $\mathrm{N}$ & \multicolumn{2}{|c|}{ Greek letters } \\
\hline$F_{\mathrm{R}}$ & Radial force, $\mathrm{N}$ & $\beta$ & Mean summit radius, $\mathrm{m}$ \\
\hline$H$ & Bearing hardness, $\mathrm{Pa}$ & $\eta$ & Dynamic viscosity, Pa.s \\
\hline$H_{\mathrm{s}}$ & Nominal gap height & $\phi$ & Flow/shear/contact factor \\
\hline $\bar{h}$ & Average film thickness, m & $\varphi$ & Bearing angle, deg \\
\hline$h$ & Nominal film thickness / surface & $\sigma_{\mathrm{s}}$ & Summit height rms, m \\
\hline & $\begin{array}{l}\text { Nominal film thickness / surface } \\
\text { separation, } m\end{array}$ & $\delta_{\mathrm{s}}$ & Mean summit height, $\mathrm{m}$ \\
\hline$h_{\mathrm{oil}}$ & Minimum nodal oil film thickness, $\mathrm{m}$ & $\theta$ & Fill ratio \\
\hline$K$ & Elastic factor in Greenwood/Tripp model & $\mu$ & Boundary friction coefficient \\
\hline$M_{\mathrm{F}}$ & Friction torque, $\mathrm{N}$ & $\varphi_{\mathrm{s}}$ & Density distribution of all summit heights, $\mathrm{m}$ \\
\hline $\bar{p}$ & Projected pressure, $\mathrm{Pa}$ & $\tau_{\mathrm{a}}$ & Asperity shear stress, $\mathrm{Pa}$ \\
\hline$p_{\mathrm{a}}$ & Asperity contact pressure, $\mathrm{Pa}$ & $\tau_{\mathrm{h}}$ & Viscous shear stress, $\mathrm{Pa}$ \\
\hline$p$ & $\begin{array}{l}\text { Oil film pressure, } \mathrm{Pa} \\
\text { Oale }\end{array}$ & \multicolumn{2}{|c|}{ Abbreviations } \\
\hline$P_{\mathrm{f}}$ & Single asperity contact force, $\mathrm{N}$ & $\mathrm{CoF}$ & Coefficient of friction \\
\hline$p_{\text {Asperity }}$ & $\begin{array}{l}\text { Maximum nodal asperity contact } \\
\text { pressure, } \mathrm{Pa}\end{array}$ & $\begin{array}{l}\text { EHL } \\
\text { LSM }\end{array}$ & $\begin{array}{l}\text { Elasto-hydrodynamic lubrication } \\
\text { Laser scanning microscopy }\end{array}$ \\
\hline$p_{\text {oil }}$ & Maximum nodal oil film pressure, $\mathrm{Pa}$ & MBS & Multi-body simulation \\
\hline$u$ & Linear velocity, $\mathrm{m} / \mathrm{s}$ & \multicolumn{2}{|c|}{ Subscripts } \\
\hline$r$ & Bearing radius, $\mathrm{m}$ & 1 & Journal \\
\hline $\mathrm{Ra}$ & Mean roughness, $\mathrm{m}$ & 2 & Bearing \\
\hline $\mathrm{Rq}$ & Root mean square (RMS) roughness, $\mathrm{m}$ & $x$ & Sliding direction \\
\hline $\mathrm{Rz}$ & Surface roughness, $\mathrm{m}$ & $y$ & Cross direction \\
\hline
\end{tabular}

was observed only for bronze bearings. Furthermore, it was shown that boundary and mixed lubrication occurred only in the first shaft revolutions of a start-up procedure. Based upon multiple variations of material and surface roughness, the authors concluded that the frictional behavior throughout a starting procedure is directly connected to the roughness of the shaft and the bearing surfaces.

In numerical simulations, the effects of acceleration time [19], wearing-in of the bearing contour [20-22], and the surface roughness $[14,21,23,24]$ on the frictional losses of sliding bearings during starting and stopping were studied. In transient multi-body simulation (MBS) with an mixed-elasto-hydrodynamic coupling (mixed-EHL/MBS), it was shown that the breakaway friction during starting was nearly independent of the surface roughness of bearing and shaft, which is in agreement to the experimental observations by Bouyer and Fillon [18]. With increasing sliding speed, the effects of surface roughness on the transient characteristics of hydrodynamic cylindrical bearings become more prominent. In further simulation studies $[21,25]$, it was shown that the time duration of asperity contact during startup can be reduced by lowering surface roughness, which is in agreement to experimental observations [26].

Reviewing the aforementioned articles revealed that most of the experimental and simulation studies investigated the startup procedure of sliding bearings. In contrast, little attention has been given to the stopping procedures that were denoted to be evenly critical in terms of mixed-friction conditions [27].

In stopping procedures, it was shown that the transition from hydrodynamic lubrication to mixed lubrication shifts to lower rotational speeds after multiple thousand start-stop cycles due to wearing-in. 
Furthermore, it was shown that the maximum friction torque was significantly reduced with increasing number of start-stop cycles [21, 28-30]. Mokhtar et al. even observed that asperity interaction was only present after the shaft rotation fully ceased. Until then, the surfaces were separated by the lubricant [26].

Consequently, a reliable prediction of friction during start-stop operation in mixed-EHL/MBS simulation requires the consideration of wearing-in effects, i.e., asperity contact pressure reduction due to change of bearing contour and roughness. However, in engineering practice, the asperity contact pressure in sliding bearings is commonly modelled with the statistical contact model according to Greenwood and Tripp (GT) [31]. The necessary input parameters, i.e., surface parameters are often chosen on the basis of empirical knowledge and without verifying a Gaussian distribution of surface heights and summit radii. A Gaussian distribution may not be present after wearing-in [32, 33].

Therefore, the aim of this study is to elucidate the applicability of state-of-the-art empirical approaches as well as the deterministic asperity contact modelling for the prediction of friction in sliding bearings subjected to start-stop operation. For this purpose, the frictional losses in sliding bearings during startstop operation were experimentally investigated and numerically simulated in transient mixed elastohydrodynamic simulations in an MBS environment (mixed-EHL/MBS). In the experimental study, sliding bearings were subjected to 10,000 start-stop cycles with continuous friction measurements. The surface roughness of the bearings and the shaft sleeves was measured before and after the experiments. Furthermore, the new and the worn contour of the bearings was measured. In mixed EHL-simulation, the averaged Reynold's equation with flow factors according to Patir and Cheng [34, 35] was combined on the one hand with statistical and on the other hand deterministic asperity contacts models. The frictional losses during start-stop operation from transient mixed-EHL/MBS simulation were compared to the experimental results.

\section{Materials and methods}

\subsection{Materials}

In the experimental part, tests were performed with sliding bearings made of bronze CuSn12Ni2C-GCB with an average hardness of $122.5 \pm 7.5 \mathrm{HBW} 5 / 250$, a $30 \mathrm{~mm}$ diameter $D, 15 \mathrm{~mm}$ width $W$, and $25 \mu \mathrm{m}$ radial clearance. The roughness target was aimed to be at Ra $1 \mu \mathrm{m}(\mathrm{Rz} 4 \mu \mathrm{m})$. The counterbody shaft sleeve was ground-finished hardened (62 HRC) steel AISI $52100(100 \mathrm{Cr} 6)$ with a roughness of Ra $0.25 \mu \mathrm{m}$ (Rq $0.45 \mu \mathrm{m}, \mathrm{Rz} 1 \mu \mathrm{m}$ ), in accordance to automotive crankshaft journals ISO/CD 27507. All specimens were cleaned with acetone prior to testing. The bearings were lubricated with an additive-free mineral oil with a viscosity grade of ISO VG 32 (kinematic viscosities of $32 \mathrm{~mm}^{2} \cdot \mathrm{s}^{-1}$ at $40{ }^{\circ} \mathrm{C}$ and $5.35 \mathrm{~mm}^{2} \cdot \mathrm{s}^{-1}$ at $100{ }^{\circ} \mathrm{C}$ ) [36]. An additive-free mineral oil was chosen to reduce chemical reactions between oil and rubbing surfaces and their potential influence on the wear behavior.

\subsection{Methods}

\subsubsection{Sliding bearing experiments}

The friction and the wear behavior during start-stop cycles was investigated using a special test rig for sliding bearings, as shown in Fig. 1.

In this study, multiple experiments with distinct number of start-stop cycles (250/2,500/10,000-all experiments were performed in duplicate) were conducted under stationary projected pressure $\bar{p}=F_{\mathrm{R}} \cdot(D \cdot W)^{-1}$ and predefined speed profile according to Fig. 2. A projected pressure of $2 \mathrm{~N} / \mathrm{mm}^{2}$ was chosen to remain below the permissible maximum projected pressure valid for a few start-stop cycles according to DIN 31652 [37]. In each cycle, the shaft was driven from standstill to its rated operational speed at $600 \mathrm{~min}^{-1}$ and vice versa with a period of constant operation

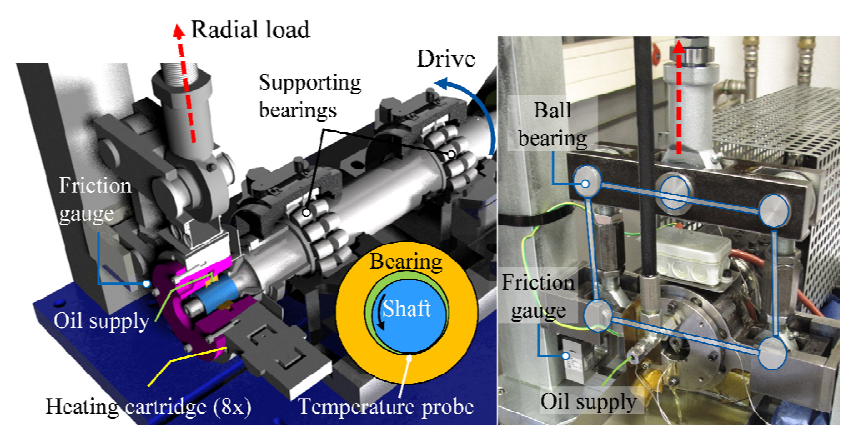

Fig. 1 Schematic and photographic representation of the bearing test rig. 
in between. The radial load was applied to the bearing housing using a flexible load unit with five lowfriction ball bearings. A friction gauge directly connected to the load unit was used to determine the friction torque without the friction torque generated in the supporting bearings. The speed, radial load, friction force as well as inlet- and bearing temperatures were continually measured during the experiments with a frequency of $100 \mathrm{~Hz}$. For each time step, the bearing's coefficient of friction $(\mathrm{CoF})$ was calculated according to $\mathrm{CoF}=M_{\mathrm{F}} \cdot\left(F_{\mathrm{R}} \cdot r\right)^{-1}$ under consideration of the measured friction torque $M_{\mathrm{F}}$, the radial force $F_{\mathrm{R}}$, and the radius of the bearing $r$. The experiments were performed under isothermal conditions regulated by circumferentially positioned heating cartridges in the bearing housing. Additionally, the oil inlet was preheated with an electrically heated hose and filtered with a micron rating of $5 \mu \mathrm{m}$. The testing parameters are summarized in Table 1.

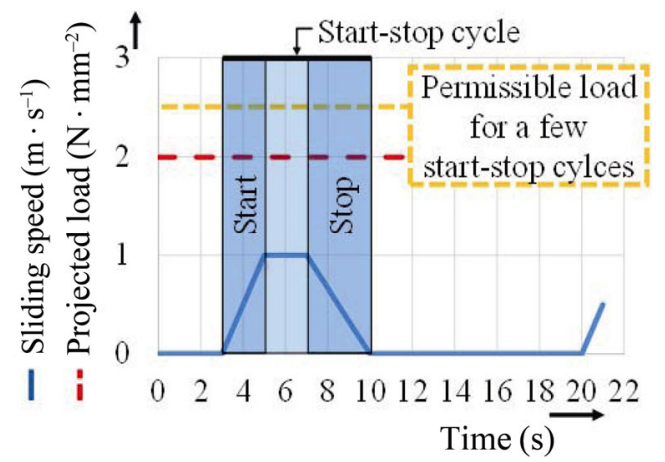

Fig. 2 Speed and load profile.

Table 1 Properties of the used oil and summarized testing parameters.

\begin{tabular}{ll}
\hline Lubricant & \\
\hline Kinematic viscosity $\left(40{ }^{\circ} \mathrm{C}\right) / \mathrm{mm}^{2} \cdot \mathrm{s}^{-1}$ & 32 \\
Kinematic viscosity $\left(100{ }^{\circ} \mathrm{C}\right) / \mathrm{mm}^{2} \cdot \mathrm{s}^{-1}$ & 5.35 \\
Testing parameters & \\
Bearing temperature $/{ }^{\circ} \mathrm{C}$ & 80 \\
Oil inlet temperature $/{ }^{\circ} \mathrm{C}$ & 70 \\
Oil inlet pressure $/ \mathrm{bar}$ & 3 \\
\hline Operating conditions & \\
\hline Stationary pressure $/ \mathrm{N} \cdot \mathrm{mm}^{-2}$ & 2 \\
Rotational speed $/ \mathrm{min}{ }^{-1}$ & $0-600$ \\
Linear speed $/ \mathrm{m} \cdot \mathrm{s}^{-1}$ & $0-0.94$ \\
Radial clearance $/ \mu \mathrm{m}$ & 25 \\
Cycle count & 250 \\
& 2,500 \\
& 10,000 \\
\hline
\end{tabular}

\subsubsection{Specimen analysis}

In this study, the bearings and the shaft sleeve's topographies were measured using a confocal laser scanning microscopy (LSM) Keyence VK-X210 (Keyence $\mathrm{GmbH}$, Neu-Isenburg, Germany). In accordance to Bergmann et al. [38], a 50-fold magnification was chosen for the determination of surface parameters from three-dimensional surface analysis for asperity contact modelling. Each measured surface patch thereby contains the height profile in an area of $141 \mu \mathrm{m} \times 141 \mu \mathrm{m}$ with a resolution of $1,000 \times 1,000$ pixels in circumferential and axial direction, respectively. After tribological testing, six measurements at randomly selected positions in the load area for each shaft sleeve and bearing were conducted. These measurements were used to evaluate the distribution of surface and summit parameters. Additionally, six measurements were performed on shaft sleeve and bearing specimen in an unloaded region. The measurement spots for this procedure are exemplarily shown in Fig. 3.

In the three dimensional (3D) surface data, asperity peaks on 3D engineering surfaces have been defined as a point higher than its eight neighbors, referred to $8 \mathrm{P}+1$ [39] or 9PP-3D [40]. The radii were determined via curve fitting over the eight nearest neighbors [40]. The bearing contour in new state and after 10,000 cycles was measured with a form tester (MarForm MMQ 100 with probe T2W Mahr, Göttingen, Germany).

\subsubsection{Simulation workflow}

The frictional losses in sliding bearings subjected to start-stop cycles under steady load and temperature were investigated in numerical simulations. In these transient mixed-EHL/MBS simulations, the topography,

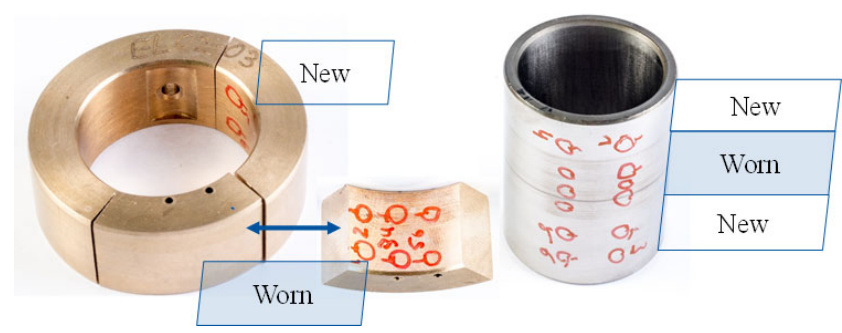

Fig. 3 Positions and distribution of surface parameter measurements on bearing and shaft sleeve. 
i.e., roughness and bearing contour, has been considered as boundary conditions. The measured bearing contour was deterministically implemented in the simulations. In contrast, the influence of roughness on the oil film pressure (micro-hydrodynamics) was considered through flow factors obtained from flow-simulations on the microscopic scale. Both, the statistical contact model according to Greenwood and Tripp (GT) [31] and the deterministic model according to Herbst [40] were employed for the asperity contact pressure calculation between two rough surfaces.

\subsubsection{Statistical contact model according to Greenwood} and Tripp (GT) [31]

The asperity contact $p_{\mathrm{a}}$ between two rough surfaces with the asperity density $\eta_{\mathrm{s}}$, mean summit radius $\beta$ and root-mean-square summit height $\sigma_{\mathrm{s}}$ and mean Young's modulus is calculated in terms of the nominal gap height $H_{\mathrm{s}}$.

$$
p_{\mathrm{a}}=\frac{16 \cdot \sqrt{2 \pi}}{15} \cdot\left(\eta_{\mathrm{s}} \beta \sigma_{\mathrm{s}}\right)^{2} \cdot \sqrt{\frac{\sigma}{\beta}} \cdot E^{*} \cdot F_{5 / 2}\left(H_{\mathrm{s}}\right)
$$

In the original work, $F_{5 / 2}\left(H_{s}\right)$ is the probability density function of the load carrying asperities with the height $s$.

$$
F_{5 / 2}\left(H_{s}\right)=\frac{1}{\sqrt{2 \pi}} \int_{H_{s}}^{\infty}\left(s-H_{s}\right)^{2.5} \mathrm{e}^{\frac{-s^{2}}{2}} \mathrm{~d} s
$$

For numerical implementation, a simplified formulation was introduced by Hu et al. [41], as shown in Eq. (3).

$$
F_{5 / 2}\left(H_{\mathrm{s}}\right)=\left\{\begin{array}{c}
4.4086 \times 10^{-5}\left(4-H_{\mathrm{s}}\right)^{6.804}, H_{\mathrm{s}}<4 \\
0, H_{\mathrm{s}} \geq 4
\end{array}\right.
$$

The input quantities are obtained from elastic material properties and the surface parameters of both surfaces (Eqs. (4-9)). It is worth to point out that Eqs. (6-9) are limited to statistically independent rough surfaces. After wearing-in, a Gaussian distribution may not be present $[32,33]$. Consequently, the modelling of worn-in asperity contacts with the GT-model may lead to inaccuracies. In Eq. (4), the mean summit height $\bar{\delta}_{\mathrm{s}}$, which defines the distance between centerlines of the roughness height and summit roughness height, is introduced, to ensure a proper application of the contact model in the mixed lubrication model.

$$
\begin{gathered}
H_{\mathrm{s}}=\frac{h-\bar{\delta}_{\mathrm{s}}}{\sigma_{\mathrm{s}}} \\
\frac{1}{E^{*}}=\frac{1-v_{1}^{2}}{E_{1}}+\frac{1-v_{2}^{2}}{E_{2}} \\
\sigma_{\mathrm{s}}=\sqrt{\sigma_{\mathrm{s}_{1}}^{2}+\sigma_{\mathrm{s}_{2}}^{2}} \\
\bar{\delta}_{\mathrm{s}}=\bar{\delta}_{\mathrm{s}_{1}}+\bar{\delta}_{\mathrm{s}_{2}} \\
\eta_{\mathrm{s}}=\sqrt{\eta_{\mathrm{s}_{1}}^{2}+\eta_{\mathrm{s}_{2}}^{2}} \\
\beta^{-1}=\beta_{\mathrm{s}_{1}}{ }^{-1}+\beta_{\mathrm{s}_{2}}^{-1}
\end{gathered}
$$

In engineering practice, the product of asperity density $\eta_{\mathrm{s}}$, mean summit radius $\beta$, and summit height distribution $\sigma_{\mathrm{s}}$ has been set to values between $\eta_{\mathrm{s}} \beta \sigma_{\mathrm{s}}=0.02$ and 0.1 , based on the experimental observations [42, 43]. It is worth to point out that positive and negative deviations from this range were reported [33, 44]. Following the same idea, Beheshti and Khonsari [42] reviewed several manuscripts and suggested a variation range for $\sigma / \beta$ between 0.0001 and 0.1. For further simplification, it is common to simplify the model by combining surface properties of asperity density, summit height, and mean summit radius within the so called elastic factor $K$ [45].

$$
K=\frac{16 \cdot \sqrt{2 \pi}}{15} \cdot\left(\eta_{\mathrm{s}} \beta \sigma_{\mathrm{s}}\right)^{2} \cdot \sqrt{\frac{\sigma_{\mathrm{s}}}{\beta}}
$$

The elastic factor $K$ represents the slope of the asperity pressure over gap height.

$$
p_{\mathrm{a}}=K \cdot E^{*} \cdot F_{5 / 2}\left(H_{\mathrm{s}}\right)
$$

It is straightforward to conclude that the elastic factor strongly influences the calculated asperity contact pressure. Under consideration of the variation range of surface parameters $\left(\eta_{\mathrm{s}} \beta \sigma_{\mathrm{s}}\right.$ and $\left.\sigma / \beta\right)$, Hu et al. [41] and Xiang et al. [46] chose an elastic factor of $K=0.000119\left(\eta_{\mathrm{s}} \beta \sigma_{\mathrm{s}}=0.05, \sigma / \beta=0.01\right)$. However, it should be noted that $K$ may vary between 0.000019 and 0.015 with the aforementioned variation range. Consequently, the computed asperity contact pressure at a specific gap height would change by almost three orders of magnitude. In other works, an elastic factor $0.0003<K<0.003$ was suggested for piston rings and sliding bearings [47]. This refinement reduces 
the potential deviation to one order of magnitude. Based upon this uncertainty, the aim of this study is to elucidate the applicability of these empirical approaches for the prediction of friction in sliding bearings subjected to start-stop operation. Therefore, in this study, a variation of the elastic factor $K$ in the range of $0.0003<K<0.003$ was considered.

\subsubsection{Deterministic contact modelling}

In order to evaluate the statistical asperity contact model according to Greenwood and Tripp (GT) [31], the asperity contact pressure $p_{\mathrm{a}}(h)$ and the real area of contact $A_{\mathrm{a}}(h)$ (Eqs. (12) and (13)) were compared to calculations by the deterministic contact model according to Herbst [40]. The equations are solved numerically for a number of given surface separations to determine a relationship between gap height and mean asperity contact pressure. The two measured surfaces are treated as one composite rough and one ideal flat surface.

$$
\begin{gathered}
p_{\mathrm{a}}(h)=\eta_{\mathrm{s}} \int_{z_{\mathrm{s}}=h}^{\infty} P_{\mathrm{f}}\left(z_{\mathrm{s}}-h\right) \varphi_{\mathrm{s}}\left(z_{\mathrm{s}}\right) \mathrm{d} z_{\mathrm{s}} \\
A_{\mathrm{a}}(h)=\eta_{\mathrm{s}} A \int_{z_{\mathrm{s}}=h}^{\infty} A_{\mathrm{f}}\left(z_{\mathrm{s}}-h\right) \varphi_{\mathrm{s}}\left(z_{\mathrm{s}}\right) \mathrm{d} z_{\mathrm{s}}
\end{gathered}
$$

Within the deterministic model, the actual distribution $\varphi_{s}\left(z_{s}\right)$, the location of summit heights and the asperity radii are taken into account. The asperity contact force $P_{\mathrm{f}}$, area $A_{\mathrm{f}}$, and pressure $p_{\mathrm{mHertz}}$ of a single asperity are determined by Hertzian equations as a function of compliance $w$ of the contacting surfaces (Eqs. (14-17)). If the local pressure exceeds the critical yield stress $Y$ of the bearing material $\left(p_{\mathrm{m}}>1.16 Y\right.$, with $\left.Y=H / 2.75\right)$, the asperity deformation is expected to show elasto-plastic up to plastic behavior, which is treated in a semi-analytical relationship [40].

$$
\begin{gathered}
P_{\mathrm{f}}=\left(\frac{4}{3}\right) E^{*} \beta^{\frac{1}{2}} w^{\frac{3}{2}} \\
\text { with } \frac{1}{E^{*}}=\frac{1}{E_{1}^{*}}+\frac{1}{E_{2}^{*}}, \quad E_{1,2}^{*}=\frac{E_{1,2}}{\left(1-v_{1,2}\right)^{2}} \\
A_{\mathrm{f}}=\pi \beta w
\end{gathered}
$$

$$
p_{\text {mHertz }}=\frac{4 E^{*}}{3 \pi} \cdot\left(\frac{w}{\beta}\right)^{\frac{1}{2}}
$$

The contact model was applied to calculate the asperity contact pressure between the measured bearing and shaft sleeve surface spots. Here, six randomly distributed measurement spots from each bearing and each shaft sleeve as described in Section 2.2.2 were used as input. Combinations for all measurement spots were evaluated, which resulted in 36 results individual results of asperity contact pressure as a function of gap height. Due to the fact that each LSMmeasurement only represents a small patch of the bearing and shaft surface, the results of this approach strongly depend upon the chosen contact pair. Thus, an averaged asperity contact pressure $p_{\mathrm{a}}(h)$ and the real area of contact $A_{\mathrm{a}}(h)$ were determined from the individual results of the measured contact pairs. Additionally, the contact pressure was calculated for the contact between the measured shaft sleeve and synthetically worn bearing surfaces. The synthetically worn bearing surfaces were created with method described in Ref. [28]. For the reader's convenience, a short summary is given here. First, for each point in width direction, the maximum peak asperity in circumferential direction was taken from the LSM-measurements of the shaft sleeve. The resulting line of maxima was inverted. As reported by Mokthar et al., bearing surface roughness after repeated starting and stopping was approximately the same as that of the hardened shaft [48]. Therefore, the inverted peak asperities from the shaft sleeve were elongated to the LSM-dimensions and then used as synthetically worn bearing surface for deterministic contact modelling. In this case, the measured shaft sleeve topography is used as the counterbody. A 2D-line scan of bearing roughness and inverted peak asperities is exemplarily shown in Fig. 4.

In this procedure, the actual location and dimensions of grooves and ridges created by summits and valleys (familiarity factor) were taken into account when calculating the asperity contact pressure. In contrast, the familiarity factor was not considered in the asperity contact pressure curves derived from the measured bearing and shaft sleeve topographies as the measurements were performed in random positions on the worn surface. 


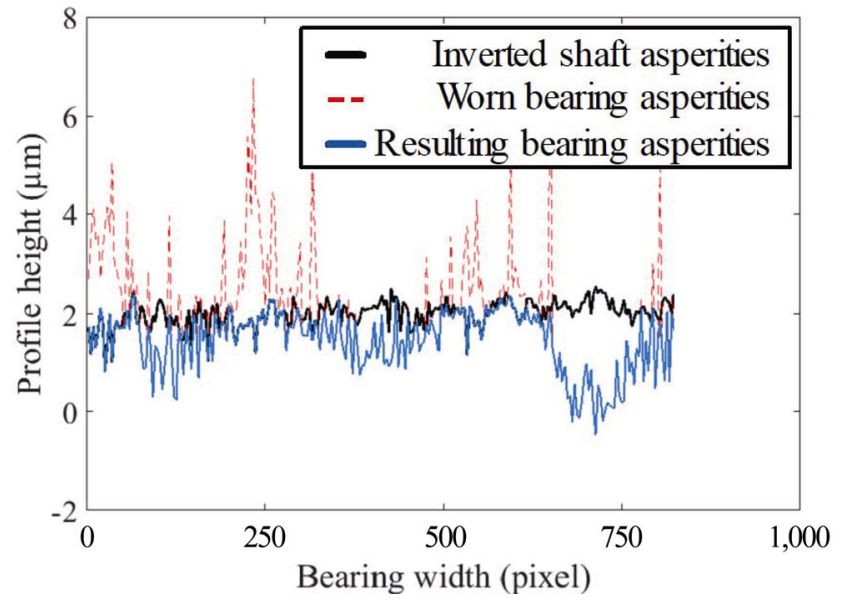

Fig. 4 Removal of bearing surface topography due to wear.

\subsubsection{Mixed EHL-simulation}

In the present study, mixed EHL-simulations were performed in AVL Excite PowerUnit 2017 (AVL List $\mathrm{GmbH}$, Graz, Austria). The software is widely used for simulation of sliding bearing systems in mixed-friction regime [16, 20, 21, 49]. In the software, the interface between shaft and sliding bearing is discretized in circumferential and axial direction. Here, a discretization of 120 nodes in circumferential and 12 nodes in axial direction to depict the hydrodynamic calculation mesh was chosen. The specimens' macroscopic contour can thereby be taken into account. For each node and time step, the load sharing concept is used to determine the ratio of hydrodynamic to asperity contact pressure. Thereby, the total normal pressure resulting from the external load equals to the sum of the total quantities for hydrodynamic and asperity pressure, as shown in Eq. (14).

$$
p_{\text {Total }}=p+p_{\mathrm{a}}
$$

The hydrodynamic pressure distribution in the bearing interface is determined by solving the averaged Reynold's equation by finite volume approach. The averaged Reynold's equation includes the effect of surface roughness onto the oil flow by the addition of flow factors as introduced by Patir and Cheng $[34,35]$. These flow factors were numerically determined in flow simulations on the measured surface patches obtained with LSM. The procedure is further explained in Refs. [17, 32]. Furthermore, the extended Reynold's equation is modified by substituting the nominal gap height $h$ by an average gap height $\bar{h}$ according to $\mathrm{Wu}$ and Zheng [50], which is the mean distance of the centerlines when the deformation due to asperity collision is considered. In the averaged Reynold's equation as shown in Eq. (15), the lubricant gap height $h$ and hydrodynamic pressure $p$ can be calculated for each circumferential position, axial position and time-step, represented by $x, y, t$, respectively. The oil viscosity $\eta$ and sliding speeds $u_{1}$ and $u_{2}$ of both shaft and bearing are necessary input values. The averaged Reynolds equation is extended by the mass conserving cavitation algorithm by Jacobson-Floberg-Olsson (JFO) [51]. Therefore, the fill ratio $\theta$ is added to prevent pressure built-up in cavitation regions of the bearing.

$$
\begin{aligned}
\frac{\partial}{\partial x}\left(\theta \phi_{p, x} \frac{h^{3}}{12 \eta} \frac{\partial p}{\partial x}\right) & -\frac{\partial}{\partial y}\left(\theta \phi_{p, y} \frac{h^{3}}{12 \eta} \frac{\partial p}{\partial y}\right)+\frac{\partial}{\partial x}\left(\theta \bar{h} \frac{u_{1}+u_{2}}{2}\right) \\
+ & \frac{\partial}{\partial x}\left(\theta \phi_{s} \frac{u_{1}-u_{2}}{2} \sigma_{s}\right)+\frac{\partial(\theta \bar{h})}{\partial t}=0
\end{aligned}
$$

Based on the observations by Bouyer and Fillon [18], a stationary boundary coefficient of friction has been added as a parameter $(\mu=0.2)$ to the mixed-EHL simulation. The local asperity shear stress on the bearing shell $\tau_{\mathrm{a}}$ is the product of $\mu$ and the mean asperity contact pressure $p_{\mathrm{a}}$ (16).

$$
\tau_{\mathrm{a}}=-p_{\mathrm{a}} \cdot \mu
$$

Furthermore, the viscous shear stress caused by the lubricant under mixed lubrication is calculated according to Eq. (17) with shear stress factors $\left(\phi_{\mathrm{f}}, \phi_{\mathrm{fs}}, \phi_{\mathrm{fp}}\right)$. The indices $i=1,2$ refer to the journal and to the bearing shell, respectively.

$$
\tau_{\mathrm{h}}=\theta\left\{\begin{array}{c}
\eta \frac{\left(u_{2}-u_{1}\right)}{h}\left(\phi_{\mathrm{f}}+\phi_{\mathrm{fs}}\right)+\phi_{\mathrm{fp}} \frac{h}{2}\left(\frac{\partial p}{\partial x}\right) \\
-\frac{\sigma_{\mathrm{i}}}{\sigma}\left(\left(\phi_{\mathrm{fp}} h-\bar{h}_{T}\right)\left(\frac{\partial p}{\partial x}\right) \mathrm{d} x-2 \eta \frac{u_{2}-u_{1}}{h} \phi_{\mathrm{fs}} \mathrm{d} x\right)
\end{array}\right\}
$$

In the following step, both viscous and asperity shear stress are integrated over the bearing surface to calculate the total friction force of the bearing.

$$
F_{\mathrm{f}}=\iint_{A}\left(\tau_{\mathrm{h}}+\tau_{\mathrm{a}}\right) \mathrm{d} A
$$


The latter can be used to calculate the bearing $\mathrm{CoF}$ using the bearing radial load $\left(F_{\mathrm{R}}\right)$.

$$
\mathrm{CoF}=\frac{F_{\mathrm{f}}}{F_{\mathrm{R}}}
$$

\section{Results and discussion}

In order to further explore and elucidate the applicability of state-of-the-art empirical approaches for the prediction of friction in sliding bearings subjected to start-stop operation, the sliding bearing test rig was transferred into a mixed-EHL/MBS simulation model. For an accurate modeling of the sliding bearing system, the bearing contour and surface roughness were measured and used as input for asperity contact modelling. Multiple simulation runs were performed. Variations include the use of the statistic asperity contact model according to Greenwood and Tripp (see Section 2.2.4.) and the deterministic asperity contact model according to Herbst (see Section 2.2.5.). The models were used with varying input parameters, i.e., empirical input parameters and input parameters from surface roughness measurements (new state and after 10,000 start-stop cycles). Furthermore, a synthetically worn-in bearing surface was used in the deterministic contact model (see Section 2.2.5.). The calculated friction losses are compared to the experimental results.

\subsection{Surface analysis for asperity contact modelling}

As a consequence of frequent start-stop operation, the wear-induced changes of the surface topography have to be considered for the asperity contact modeling. The evolution of the input parameters for the GTmodel from new state to the state after 10,000 startstop cycles and the change of bearing contour are shown in Fig. 5.

A significant change of the combined summit roughness $\sigma_{\mathrm{s}}$ can be observed in the first hundred start-stop cycles (Fig. 5(a)). This change can mainly be attributed to wearing-in of the sliding bearing whereas the shaft sleeve was not subjected to significant change. After 10,000 start-stop cycles, the summit roughness of the bearing becomes slightly
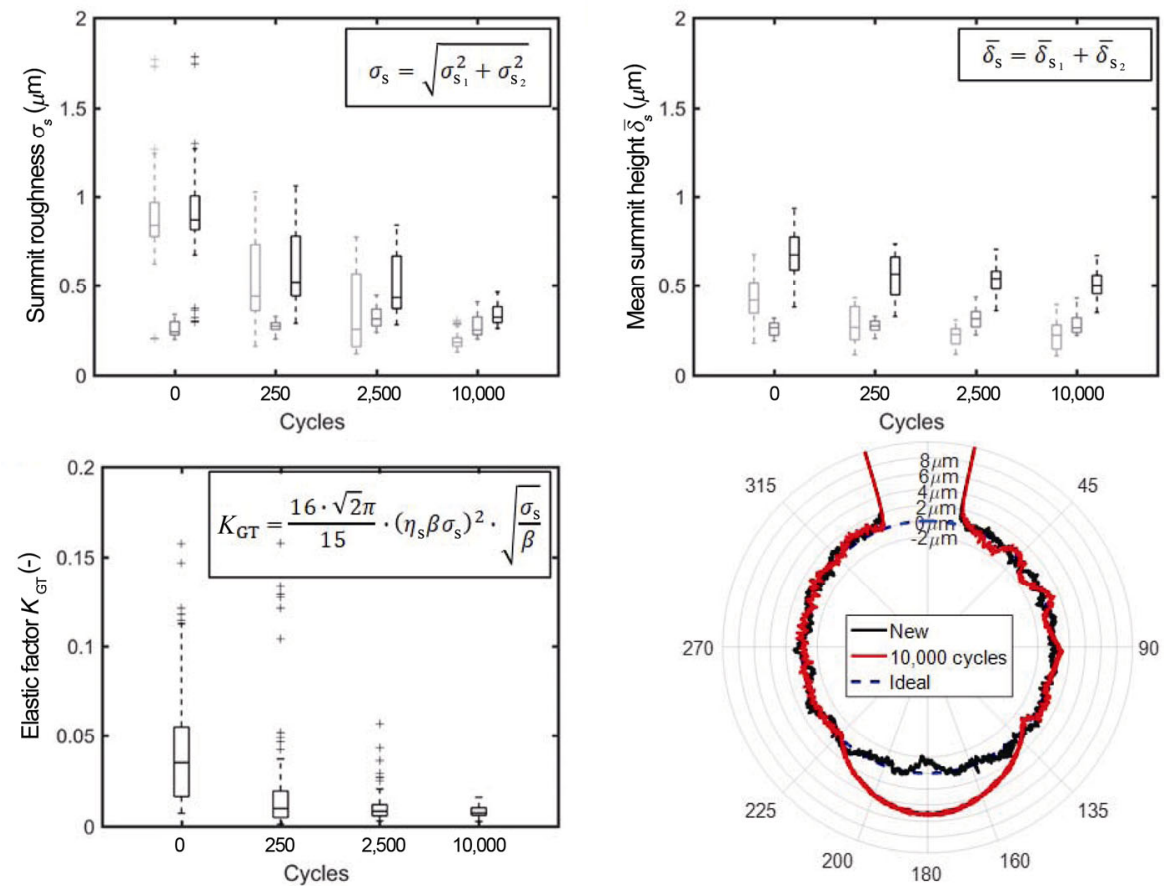

Fig. 5 Evolution for Greenwood/Tripp model parameters during 10,000 start-stop cycles. The first boxplot (light grey) at each cycle count is derived from values from the bearings, the second boxplot (grey) for the shaft sleeve. For the third boxplot (black) the values of bearing and shaft sleeve were combined according to Eqs. (5-9) in the methods section: (a) summit roughness, (b) mean summit height, (c) elastic factor, and (d) measured change of bearing contour after 10,000 start-stop cycles. 
smoother than the roughness of the counterbody (shaft sleeve). Furthermore, the mean summit height of the bearing's surface becomes lower than the mean summit height of the shaft sleeve, which is not subjected to change (Fig. 5(b)). With a value of $K=$ 0.038 , the analytically determined elastic factor $K$ for the new state was more than twelve times higher than the suggested value range $(0.0003<K<0.003)$. Even after 10,000 start-stop cycles, the mean elastic factor $K=0.0075$ was two times higher than the suggested value range. The measured wear contour was smoothed in order to separate roughness scale from macroscopic scale. The bearing's macroscopic contour, which is used in the mixed-EHL/MBS simulation model, is shown in Fig. 6.

\subsection{Asperity contact pressure}

The asperity contact pressure curves for all cases in new state and after 10,000 start-stop cycles are shown in Fig. 7.

For the deterministic contact model, the transition gap height between hydrodynamic and mixed friction is at $4.5 \mu \mathrm{m}$ in new state (Fig. 7(a)). The use of GTmodel estimates a lower transition gap height at

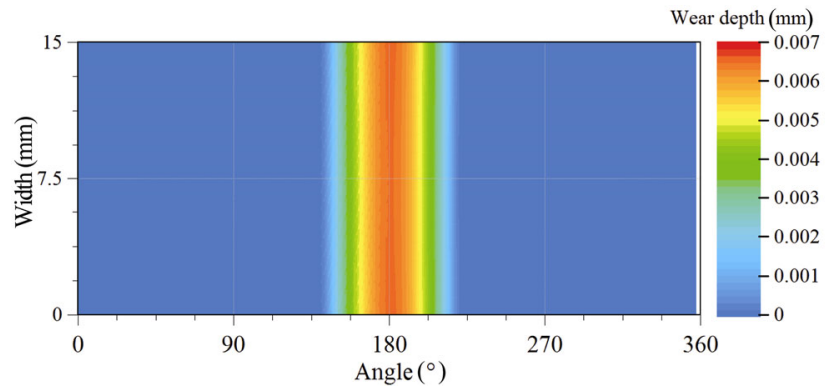

Fig. 6 Worn bearing contour used for mixed-EHL/MBS simulations.

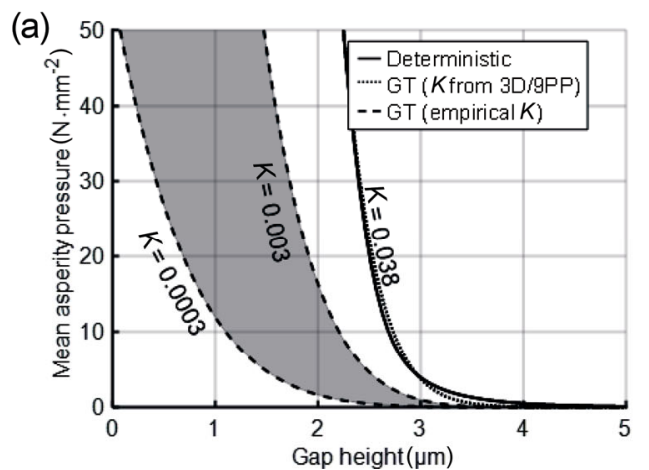

approximately $3.5 \mu \mathrm{m}$. The difference can be explained by the use of mean quantities in the stochastic model, whereas the deterministic contact model considers the actual distribution of surface height. After 10,000 start-stop cycles (Fig. 7(b)), the deterministic contact model with measured topography predicts a transition gap height at approximately $3 \mu \mathrm{m}$, whereas the GT-model predicts a lower transition gap height of $1.5 \mu \mathrm{m}(-50 \%)$, again attributed to the consideration of mean quantities. As mentioned in the method section, the calculated asperity contact curve from the deterministic contact model with a synthetically worn bearing surface introduces a new interdependency into contact modelling that is not present in the previous approaches. In the deterministic contact model with familiarity factor (Det. with familiarity), the asperity contact pressure curves are generated with a synthetically worn bearing surface. In this case, the maxima of the inverted shaft sleeve topography has been used as a counterbody for the synthetically worn bearing surface (see Fig. 4). The dependency of the actual height and location of summits is thereby considered. This "familiarity factor" implicates the compatibility of asperity summits and valleys after a certain period of mixed friction operation. Taking this into account, a transition gap height of $0.75 \mu \mathrm{m}$ can be observed, which is significantly lower $(-75 \%)$ in comparison to the deterministic asperity contact of two randomly positioned surface measurements.

\subsection{Mixed-EHL/MBS simulation}

The results of mixed-EHL/MBS simulation for new state and after 10,000 start-stop cycles are shown in Fig. 8.

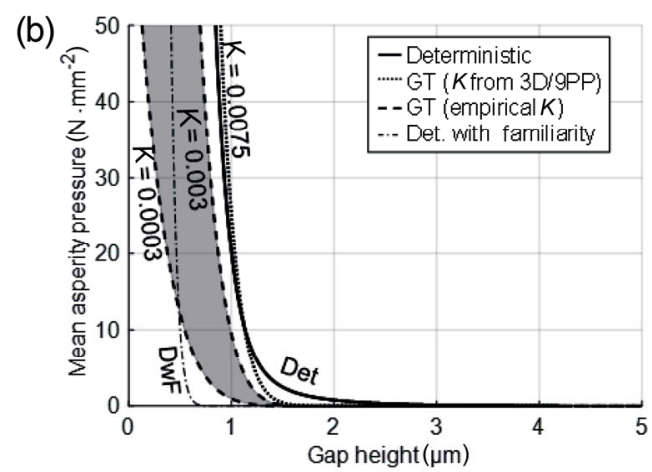

Fig. 7 Comparison of contact pressure curves for the deterministic and Greenwood/Tripp contact model: (a) new state, and (b) after 10,000 start-stop cycles. 

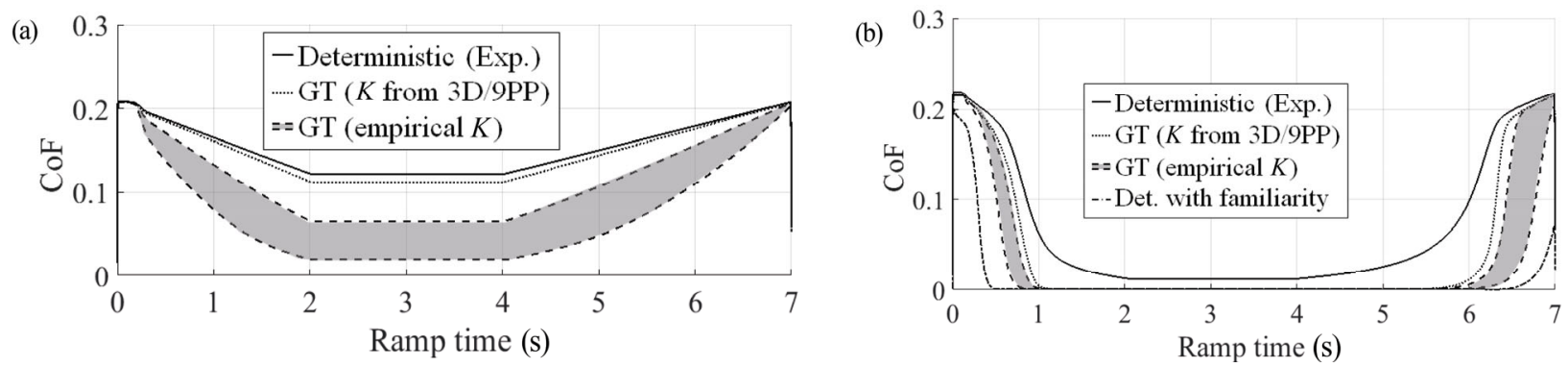

Fig. 8 Evolution of coefficient of friction (CoF) with the stochastic contact model according to Greenwood and Tripp (GT) and deterministic contact model according to Herbst: (a) new state, and (b) after 10,000 start-stop cycles.

For the first start-stop cycle (Fig. 8(a)), the stochastic and deterministic contact models predict similar friction losses at the beginning and the end of the start-stop cycle. This can be traced back to the fact that a large proportion of load is carried by the asperities at low rotational speeds. After two seconds, when the bearing operates in steady-state operation, the deterministic contact model predicts higher frictional losses, which can be explained by the larger gap height for transition from mixed to hydrodynamic lubrication (Fig. 8(a)). Independent of the chosen asperity contact model, the relatively high frictional losses during the steady-state operation indicate that the sliding bearing still operates under mixed friction conditions. However, it is worth to point out that the variation the elastic factor $K$ in the statistical contact model leads to large differences (200\%) in the predicted frictional losses.

After 10,000 cycles (Fig. 8(b)), the deterministic model with surface measurements from random positions in the load area leads to a high frictional losses throughout the start-stop cycle with a significant rise of $\mathrm{CoF}$ during stopping. The relatively high frictional losses during the steady-state operation indicate that the bearing still operates under mixed friction conditions.

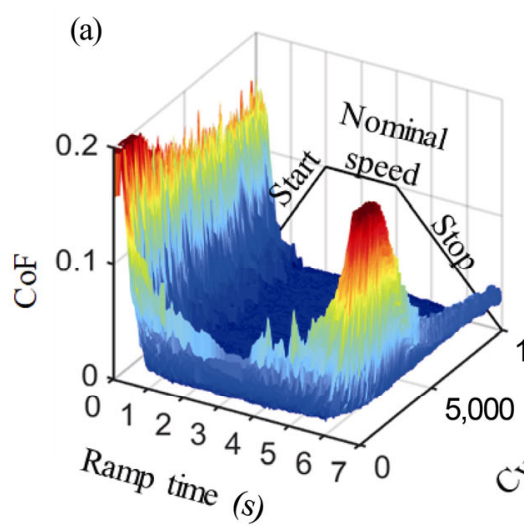

(b)

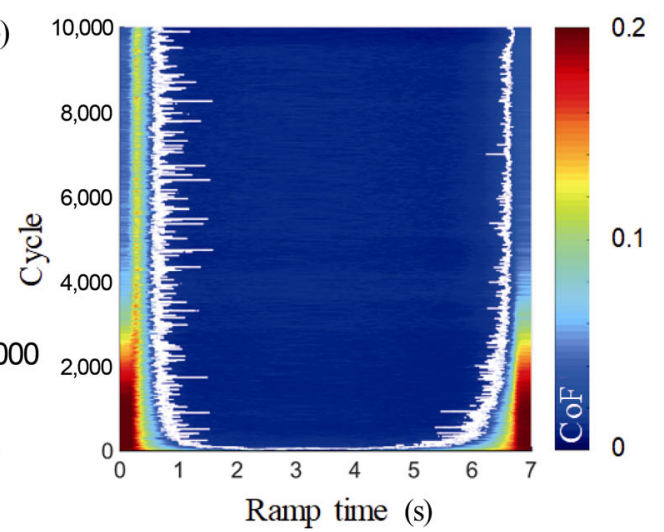

Fig. 9 Measured frictional losses (CoF) during 10,000 start-stop cycles: (a) 3D view, and (b) 2D top view.
A similar breakaway friction can be observed for the GT approach with empirical $K$ values. In contrast to the deterministic model, the $\mathrm{CoF}$ decreases more rapidly and after one second, low friction losses can be observed. A similar trend can be seen during stopping, where the CoF begins to rise one second before the rotation ceases. For the simulation results with deterministic asperity contact with familiarity factor, a transition from high to low friction after 0.6 seconds can be observed. The effect is even more pronounced in the stopping phase, where a slight rise of $\mathrm{CoF}$ is only observed within the 0.25 seconds of the start-stop cycle (Fig. 8(b)).

\subsection{Comparison of simulated and experimental frictional losses}

To visualize the CoF evolution throughout the experiment, the standstill periods were cropped from further evaluation and all start-stop cycles were aligned. An arbitrary white line was added to highlight where the $\mathrm{CoF}$ reached values lower than 0.02 . Thereby, the transition to hydrodynamic regime can be estimated. The frictional losses (CoF) during 10,000 start-stop cycles are shown in Fig. 9. 
During the initial start-stop cycles, a constant breakaway $\mathrm{CoF}$ of approximately 0.2 was observed (Fig. 9(a)). In these first cycles, the CoF remains high at nominal speed which emphasizes that asperity contact is still present at this point of operation. A similar behavior is observed in the mixed-EHL/MBS simulations (Fig. 8(a)). Within the first few hundred start-stop cycles, the CoF during breakaway of 0.2 remains nearly stationary. After that period, a slight decrease towards 0.16 and a shift of the maximum value to higher rotational speeds can be observed. This can be explained by the experimental observations by Mokhtar et al., where the shaft initially rotated along the bearing wall before the build-up of hydrodynamic pressure led to sliding motion [26]. During stopping, the CoF of 0.2 continuously decreases after a few hundred start-stop cycles, which can be explained by the improved build-up of hydrodynamic pressure and reduced asperity interaction between worn-in surfaces [20, 21]. In Fig. 9(b), the evolution of the hydrodynamic regime is shown. After the initial period of wearing-in, the time for the transition from mixed lubrication to hydrodynamic lubrication reaches a steady value of 0.5 seconds which equals to a speed of approximately $0.5 \mathrm{~m} / \mathrm{s}$. These observations clarify the experimental observations of Mokthar et al. [48], where mixed-friction conditions were predominantly present in the startup phase. The measured and simulated coefficient of friction (CoF) within the $1^{\text {st }}$ and within the $10,000^{\text {th }}$ start-stop cycle are exemplarily shown in Fig. 10.

In the first start-stop cycle (Fig. 10(a)), a rise of $\mathrm{CoF}$ associated with the breakaway friction can be observed at startup. The acceleration of the shaft to nominal speed only leads to a slight reduction with still notably high frictional losses with an average CoF above 0.1 during the nominal speed operation. During stopping, the $\mathrm{CoF}$ rises again until reaching a value 0.2 . Comparing the experimental results to the numerical results, the use of the deterministic contact model and the statistical contact model with surface parameters from surface measurements lead to an overestimation of the frictional losses as the average $\mathrm{CoF}$ is in the range of 0.1 . This may be caused by abrupt wearing-in of peak asperities. Consequently, the frictional losses would be reduced. In contrast, the GT model with empirical $K$ assumes a CoF below
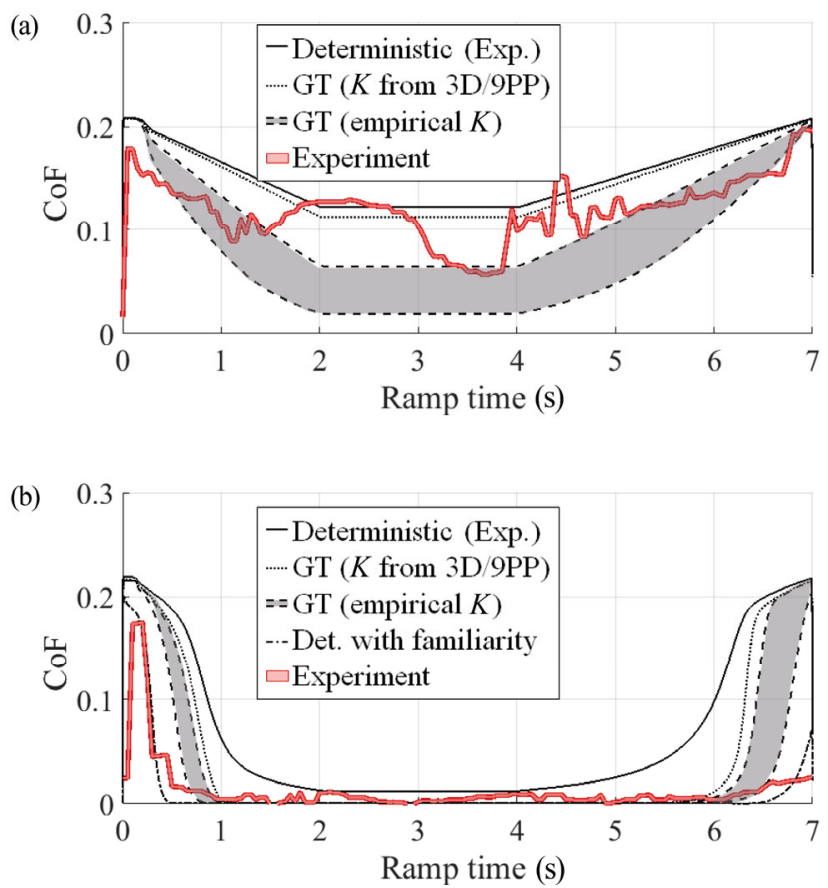

Fig. 10 Comparison of measured and simulated CoF: (a) $1^{\text {st }}$ start-stop cycle and (b) $10,000^{\text {th }}$ start-stop cycle.

0.06 . Especially the use of $K=0.0003$ clearly underestimates the frictional losses.

After 10,000 start-stop cycles (Fig. 10(b)) the frictional losses throughout the predefined start-stop cycle are significantly reduced. With the initial breakaway, the $\mathrm{CoF}$ increases to a value of 0.18 which is comparable to the $\mathrm{CoF}$ during starting in the first cycle. With increasing speed, a low CoF can be observed that remains below 0.02 through the start-stop cycle. During stopping, the CoF only slightly increases to 0.04 before the rotation ceases. By comparing the simulation and experimental results, it is obvious to see that neither the deterministic contact model with data random positions surface measurements nor the statistic contact model with empirical values for $K$ meets the requirements of predicting the frictional losses after 10,000 start-stop cycles. During startup, the frictional losses rapidly decrease which cannot be observed in both models. During steady-state operation, all models predict low frictional losses, whereas the measurements show slightly higher losses that may be caused by viscous shearing of the lubricant. During stopping, the experimental CoF only increases slightly. In contrast, the deterministic contact model with data of random positioned surface measurements and the statistic contact model with 
empirical values for $K$ show a significant increase of CoF. The deterministic contact model with a synthetically worn bearing surface shows a rather similar CoF during startup, followed by a reduction within the first 0.5 seconds, which is in agreement to the experimental observations. Furthermore, the later onset of asperity interaction (Fig. 7(b)) results in a slight increase of $\mathrm{CoF}$ during stopping, which is in agreement to the experimental observations in Fig. 10(b). The slight increase of CoF can be explained by the negligible asperity interaction during stopping, which was also observed by Mokhtar et al. [26].

\section{Conclusions and outlook}

The aim of this study was to predict the frictional losses in sliding bearings subjected to start-stop operation. For this purpose, the frictional losses of sliding bearings in start-stop operation were investigated experimentally and in transient mixed elasto-hydrodynamic simulations in a multi-body simulation environment (mixed-EHL/MBS). Both experiments and simulations show that the frictional losses during sliding bearing start-stop operation are significantly affected by the wearing-in of a bearing surface. In the present study, the initially high surface roughness leads to higher frictional losses within the first hundred start-stop cycles. Subsequently, a reduction of frictional losses was observed caused by a reduced asperity interaction in the interface of bearing and shaft. Based upon the direct comparison of experimental and numerical results, the following conclusions can be drawn:

1) Repeated start-stop operation leads to a significant reduction of frictional losses that can be linked back to wearing-in of the bearing roughness and the contour. Especially during stopping procedures, where hydrodynamic effects are present, worn-in bearings show reduced frictional losses as they operate without asperity interaction until very low sliding speeds.

2) For sliding bearing systems in new state, a deterministic contact model with randomly distributed surface measurements may be used to predict the frictional losses. In contrast, the statistical asperity contact model according to Greenwood and Tripp with empirical values for the elastic factor underestimates frictional losses.
3) For sliding bearings in worn state, e.g., after 10,000 start-stop cycles, a reliable prediction of the frictional performance requires the utilization of a deterministic contact model and the consideration of the familiarity factor. The familiarity factor describes the conformity of two surfaces on asperity contact scale. Numerical simulations show that the actual position and height of surface roughness should be taken into account. The conformity is significantly improved by wearing-in and results in an improved frictional performance.

In further studies, the elaboration relocation technnique as introduced by Furustig et al. [52] should be considered. Additionally, the utilization of advanced friction models for mixed lubrication conditions should be evaluated for further improvements, e.g., Refs. [53, 54].

\section{Acknowledgements}

This work was funded by the Deutsche Forschungsgemeinschaft (DFG, German Research Foundation)GRK 1856.

Open Access: This article is licensed under a Creative Commons Attribution 4.0 International License, which permits use, sharing, adaptation, distribution and reproduction in any medium or format, as long as you give appropriate credit to the original author(s) and the source, provide a link to the Creative Commons licence, and indicate if changes were made.

The images or other third party material in this article are included in the article's Creative Commons licence, unless indicated otherwise in a credit line to the material. If material is not included in the article's Creative Commons licence and your intended use is not permitted by statutory regulation or exceeds the permitted use, you will need to obtain permission directly from the copyright holder.

To view a copy of this licence, visit http://creativecommons.org/licenses/by/4.0/.

\section{References}

[1] Adam A, Prefot M, Wilhelm M. Crankshaft bearings for engines with start-stop systems. MTZ Worldw 71(12): 
22-25 (2010)

[2] Gudin D, Mian O, Sanders S. Experimental measurement and modelling of plain bearing wear in start-stop applications. Proc Inst Mech Eng, Part J: J Eng Tribol 227(5): 433-446 (2013)

[3] Garnier T. EHD+T analysis and calibration investigate the effect of the waviness of a rod crankpin. Ulm, 2018.

[4] Knorr R. Start/stopp-systeme auf der zielgeraden. ATZ-Automobiltech Z 113(9): 664-669 (2011)

[5] Wong V W, Tung S C. Overview of automotive engine friction and reduction trends-Effects of surface, material, and lubricant-additive technologies. Friction 4(1): 1-28 (2016)

[6] Ligier J L, Noel B. Friction reduction and reliability for engines bearings. Lubricants 3(3): 569-596 (2015)

[7] Holmberg K, Erdemir A. Influence of tribology on global energy consumption, costs and emissions. Friction 5(3): 263-284 (2017)

[8] Aufischer R, Walker R, Offenbecher M, Feng O, Hager $\mathrm{G}$. Friction reduction opportunities in combustion engine crank train bearings. In ASME 2015 Internal Combustion Engine Division Fall Technical Conference, Houston, Texas, USA, 2015: V002T07A008.

[9] Durak E, Adatepe H, Biyiklioğlu A. Experimental study of the effect of additive on the tribological properties journal bearing under running-in and start-up or shut-down stages. Ind Lubr Tribol 60(3): 138-146 (2008)

[10] Summer F, Grün F, Offenbecher M, Taylor S. Challenges of friction reduction of engine plain bearings - Tackling the problem with novel bearing materials. Tribol Int 131: 238-250 (2019)

[11] Grützmacher P G, Rosenkranz A, Szurdak A, König F, Jacobs G, Hirt G, Mücklich F. From lab to applicationImproved frictional performance of journal bearings induced by single-and multi-scale surface patterns. Tribol Int 127: 500-508 (2018)

[12] Grützmacher P G, Profito F J, Rosenkranz A. Multiscale surface texturing in tribology-Current knowledge and future perspectives. Lubricants 7(11): 95 (2019)

[13] König F, Rosenkranz A, Grützmacher P G, Mücklich F, Jacobs G. Effect of single-and multi-scale surface patterns on the frictional performance of journal bearings - A numerical study. Tribol Int 143: 106041 (2020)

[14] Nilsson D, Prakash B. Influence of different surface modification technologies on friction of conformal tribopair in mixed and boundary lubrication regimes. Wear 273(1): 75-81 (2011)

[15] Bartel D, Bobach L, Illner T, Deters L. Simulating transient wear characteristics of journal bearings subjected to mixed friction. Proc Inst Mech Eng, Part J: J Eng Tribol 226(12): 1095-1108 (2012)

[16] Sander D E, Allmaier H, Priebsch H H, Witt M, Skiadas A.
Simulation of journal bearing friction in severe mixed lubrication - Validation and effect of surface smoothing due to running-in. Tribol Int 96: 173-183 (2016)

[17] Grützmacher P G, Rammacher S, Rathmann D, Motz C, Mücklich F, Suarez S. Interplay between microstructural evolution and tribo-chemistry during dry sliding of metals. Friction 7(6): 637-650 (2019)

[18] Bouyer J, Fillon M. Experimental measurement of the friction torque on hydrodynamic plain journal bearings during start-up. Tribol Int 44(7-8): 772-781 (2011)

[19] Prölß M, Schwarze H, Hagemann T, Zemella P, Winking $\mathrm{P}$. Theoretical and experimental investigations on transient run-up procedures of journal bearings including mixed friction conditions. Lubricants 6(4): 105 (2018)

[20] Sander D E, Allmaier H. Starting and stopping behavior of worn journal bearings. Tribol Int 127: 478-488 (2018)

[21] Sander D E, Allmaier H, Priebsch H H. Friction and wear in automotive journal bearings operating in today's severe conditions. In Advances in Tribology. Darji P H, Ed. Rijeka: IntechOpen, 2016.

[22] Fricke S, Hager C, Solovyev S, Wangenheim M, Wallaschek J. Influence of surface form deviations on friction in mixed lubrication. Tribol Int 118: 491-499 (2018)

[23] Knoll G, Boucke A, Winijsart A, Stapelmann A, Auerbach P. Reduction of friction losses in journal bearings of valve train shaft by application of running-in profile. Tribol Schmierungstechnik 63(4): 14-21 (2016)

[24] Isaksson P, Nilsson D, Larsson R, Almqvist A. The influence of surface roughness on friction in a flexible hybrid bearing. Proc Inst of Mech Eng, Part J: J Eng Tribol 225(10): 975-985 (2011)

[25] Cui S H, Gu L, Fillon M, Wang L Q, Zhang C W. The effects of surface roughness on the transient characteristics of hydrodynamic cylindrical bearings during startup. Tribol Int 128: 421-428 (2018)

[26] Mokhtar M O A, Howarth R B, Davies P B. The behavior of plain hydrodynamic journal bearings during starting and stopping. A S L E Trans 20(3): 183-190 (1977)

[27] Affenzeller J, Gläser H. Lagerung und Schmierung von Verbrennungsmotoren. Vienna (Austria): Springer-Verlag, 1996.

[28] König F, Ouald Chaib A, Jacobs G, Sous C. A multiscale-approach for wear prediction in journal bearing systems - From wearing-in towards steady-state wear. Wear 426-427: 1203-1211 (2019)

[29] König F, Jacobs G, Sous C. Wear prediction of journal bearings in start-stop operation. In 9th VDI Conference on Cylinder Barrel, Piston, Connecting Rod 2018: The Crank Drive in the Stress Field of Different Requirements, 2018: 197-208. 
[30] König F, Jacobs G, Burghardt G. Running-in of plain bearings in start-stop operation. In 12th VDI Conference on Sliding and Rolling Bearings 2017: Design, Calculation, Use, 2017: 53-62.

[31] Greenwood J A, Tripp J H. The contact of two nominally flat rough surfaces. Proc Inst Mech Eng 185(1): 625-633 (2016)

[32] Zhang Y, Kovalev A, Hayashi N, Nishiura K, Meng Y. Numerical prediction of surface wear and roughness parameters during running-in for line contacts under mixed lubrication. J Tribol 140(6): 061501 (2018)

[33] Tomanik E. Modelling of the asperity contact area on actual 3D surfaces. SAE paper 2005-01-1864, 2005.

[34] Patir N, Cheng H S. An average flow model for determining effects of three-dimensional roughness on partial hydrodynamic lubrication. J Lubr Technol 100(1): 12-17 (1978)

[35] Patir N, Cheng H S. Application of average flow model to lubrication between rough sliding surfaces. $J \mathrm{Lubr}$ Technol 101(2): 220-229 (1979)

[36] Schilling M. Referenzöle für wälz- und Gleitlager-, Zahnrad-und Kupplungsversuche: Datensammlung für Mineralöle; Berichtszeitraum: 1976/84. Frankfurt (Germany): FVA, 1985.

[37] DIN Deutsches Institut für Normung. Gleitlagerhydrodynamische radial-gleitlager im stationären betriebTeil 3: Betriebsrichtwerte für die berechnung von kreiszylinderlagern (DIN 31652-3: 2017). Berlin: Beuth Verlag, 2017.

[38] Bergmann P, Grün F, Gódor I, Stadler G, Maier-Kiener V. On the modelling of mixed lubrication of conformal contacts. Tribol Int 125: 220-236 (2018)

[39] Kalin M, Pogačnik A. Criteria and properties of the asperity peaks on $3 \mathrm{D}$ engineering surfaces. Wear 308(1-2): 95-104 (2013)

[40] Herbst HM. Theoretical modeling of the cylinder lubrication in internal combustion engines and its influence on piston slap induced noise, friction and wear. Graz (Austria): Graz University of Technology, 2008.

[41] Hu Y Z, Cheng H S, Arai T, Kobayashi Y, Aoyama S. Numerical simulation of piston ring in mixed lubrication-A nonaxisymmetrical analysis. $J$ Tribol 116(3): 470-478 (1994)
[42] Beheshti A, Khonsari M M. An engineering approach for the prediction of wear in mixed lubricated contacts. Wear 308(1-2): 121-131 (2013)

[43] Greenwood J A, Williamson J B P. Contact of nominally flat surfaces. Proc Roy Soc A Math Phys Eng Sci 295(1442): 300-319 (1966)

[44] Tomanik E, Chacon H, Teixeira G. A simple numerical procedure to calculate the input data of GreenwoodWilliamson model of asperity contact for actual engineering surfaces. Tribol Ser 41: 205-215 (2003)

[45] Jocsak J, Tomanik E, Wong V W, Tian T. The characterization and simulation of cylinder liner surface finishes. In ASME 2005 Internal Combustion Engine Division Spring Technical Conference, Chicago, 2005: 457-467.

[46] Xiang G, Han Y F, Wang J X, Wang J F, Ni X K. Coupling transient mixed lubrication and wear for journal bearing modeling. Tribol Int 138: 1-15 (2019)

[47] AVL. AVL Power Unit Theory 2017.

[48] Mokhtar M O A, Howarth R B, Davies P B. Wear characteristics of plain hydrodynamic journal bearings during repeated starting and stopping. A S L Trans 20(3): 191-194 (1977)

[49] Allmaier H, Sander D E, Reich F M. Simulating friction power losses in automotive journal bearings. Proc Eng 68: 49-55 (2013)

[50] $\mathrm{Wu} \mathrm{C}$ W, Zheng L Q. An average Reynolds equation for partial film lubrication with a contact factor. $J$ Tribol 111(1): 188-191 (1989)

[51] Jakobsson B F L. The Finite Journal Bearing Considering Vaporization. Göteborg: Gumpert, 1957.

[52] Furustig J, Dobryden I, Almqvist A, Almqvist N, Larsson R. The measurement of wear using AFM and wear interpretation using a contact mechanics coupled wear model. Wear 350-351: 74-81 (2016)

[53] Offner G, Knaus O. A generic friction model for radial slider bearing simulation considering elastic and plastic deformation. Lubricants 3(3): 522-538 (2015)

[54] Bewsher S R, Leighton M, Mohammadpour M, Rahnejat $H$, Offner G, Knaus O. Atomic force microscopic measurement of a used cylinder liner for prediction of boundary friction. Proc Inst Mech Eng, Part D: J Autom Eng 233(7): 1879-1889 (2019) 


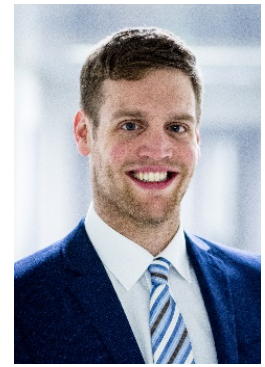

Florian KÖNIG. He received his B.S., M.S., and Ph.D. degrees in mechanical engineering from the RWTH Aachen University, Germany, focusing on mechanical engineering and tribology. Currently, he is head

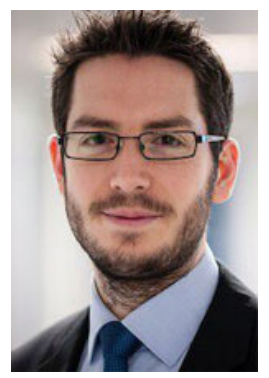

Christopher Sous. He received his B.S., M.S., and Ph.D. degrees in mechanical engineering from the RWTH Aachen University, Germany, focusing on mechanical engineering and tribology. He currently is head

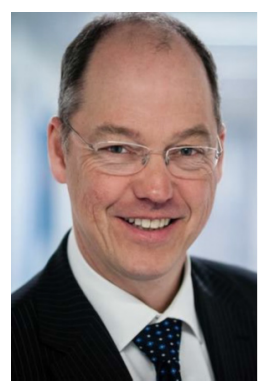

Georg JАсовs. He received his diploma and Ph.D. degree in mechanical engineering from RWTH Aachen University, Germany. Subsequently, he worked as a chief engineer at the Institute for Fluid Power Drives and Controls at RWTH Aachen University, Germany. After several years in industry, he joined the Institute of department in the field of tribology at the Institute for Machine Elements and Systems Engineering, Germany. His research interests include the friction and wear behavior of plain bearings, tribolayers, surface texturing, condition monitoring, and machine learning methods.

of department in the field of bearing technology at the Institute for Machine Elements and Systems Engineering, Germany. His research areas cover the tribological behavior and failure mechanisms of rolling and plain bearings, condition monitoring as well as material characterization.

for Machine Elements and Systems Engineering at RWTH Aachen University in 2008. His current position is a professor and the director of the institute. Since 2013 he has been director of the Chair for Wind Power Drives and speaker of the board of the Center for Wind Power Drives at RWTH Aachen University. Since 2016 he has been the director of the Chair and Institute for Engineering Design at RWTH Aachen University. 